\title{
An Investigation on English Reading Strategy Use in Major-related Materials among Native and Foreign Language Learners
}

\author{
Jianfeng Zheng \\ School of Foreign Languages, Shanxi Normal University, Linfen, Shanxi, China \\ Ning Kang \\ Graduate School, Shanxi Normal University, Linfen, Shanxi, China
}

\begin{abstract}
Researches on L2 learning strategy have always been focus in applied linguistics. Meanwhile, as one of the most vital ways to access knowledge, researches on $\mathrm{L} 2$ reading strategy attract more and more attention. However, cross-cultural comparison, especially between native learners and L2 learners, can be hardly seen in the circle of L2. This study adopts the questionnaire of the Survey of Reading Strategies (SORS) designed by Mokhtari and Sheorey (2002) to investigate the use of strategies of 149 college students (valid questionnaires) from Beihang University (BUAA) and University of Colorado Boulder (UCBoulder) majoring in Economics while reading major-related materials in English. Results of this study reveals that, firstly, the use of reading strategy for both Chinese and the US learners fall into medium to high level, and Chinese learners report a higher use of strategy in general than their American counterparts. Secondly, except meta-cognitive strategy, there are significant differences between Chinese and the US learners in cognitive and support strategy; but both the US and Chinese learners display a similar strategy preference, in other words, all learners prefer to use cognitive strategy, followed by meta-cognitive strategy and support strategy.
\end{abstract}

Index Terms - English reading strategy, major-related reading, native learners, foreign language learners

\section{INTRODUCTION}

In language learning, reading is regarded as a major source of input, and for many EFL learners, it is the most important skill in an academic context (Grabe, 1991). In addition, reading can help learners to extend their general knowledge of the world. In the context of China, as Chinese learners are learning in as acquisition-poor environment, they need to depend on reading for language and culture immersion. The crucial importance of the reading skill in academic contexts had led to considerable research on reading in a second language. However, early research in second language reading was, to a considerable extent, informed by native-language (English) reading research and was considered as simple extensions of research trends in first language reading. Much of the early research in ESL reading adopted Goodman's point of view that reading is a "psycholinguistic guessing game" during which readers can make prediction about the content of passage according to the linguistic clues as well as his prior experience. It is a complex cognitive process in which reader and the text interact to (re)create meaningful discourse (Silberstein, 2002::x). It is a kind of dialogue between the reader and the text, even between the reader and the author (Widdowson, 1999, cited in Hedge, 2002:188).

Reading strategies are defined as the mental operations involved when readers approach a text effectively and make sense of what they are reading (Barnett 1988). Many studies have provided sufficient evidence for the efficacy of strategy training (Carrel, Pharis, and Liberto, 1989, cited in Hedge, 2002:80-81; Liu and Zuo, 2006). A number of empirical investigations have been conducted to show the positive role of meta-cognitive strategies in reading comprehension (Block, 1992; Carrel, 1989; Olshavsky, 1976-1977). Alsheikh and Mokhtari (2011) examined the use of meta-cognitive strategies by native speakers of Arabic when reading in English and Arabic and found that Arabic native speakers use more strategies when reading in English than reading in Arabic. Most of the research in the reading strategies of second language learners has dealt with learners at lower levels of proficiency or those studying at the secondary school or in pre-university programs (Block, 1986; Carrell et al., 1989; Anderson, 1999). Research on the reading strategies of advanced or proficient second language learners or that comparing the strategies of such learners with those of native speakers is rare. Therefore, the present study is intended to fill that gap by reporting on a study which compares the reading strategies of Chinese college learners with those of native-English-speaking American college learners, and performs a search for a more accurate and complete characterization of second language readers.

\section{Methodology}

The main aims in this study are to find out the differences in reading strategy use between learners in China and the 
US while reading major-related materials, and the author attempts to identify the relationship between English proficiency and reading strategy use. To attain these research aims, a questionnaire is administrated to students in Beihang University and University of Colorado Boulder respectively.

\section{A. Research Questions}

The study attempts to answer the following questions:

1. What are the types and frequency of English reading strategy used by the US and Chinese learners respectively?

2. Are there any significant differences between Chinese and the US learners in their reported use of reading strategies while reading major-related materials?

\section{B. Subjects}

The subjects in this study consisted of 149 college learners ( 73 Chinese and 76 Americans). The learners, who were predominantly undergraduate seniors in China and juniors in the US, were admitted to their respective universities for full-time academic study, representing majors in Economics. Background information collected during the course of the study indicated that, among the 73 Chinese learners, 47 are males and 26 are females by gender with the average age of 22.53; among the 76 American learners, gender distribution is 51 males vs. 25 females with the mean age of 22.14 . In this study, 92 (73 available) Chinese seniors in Beihang University (BUAA) and 84 (76 available) American juniors in University of Colorado Boulder (CUBoulder) are chosen to perform a questionnaire on English reading strategies while reading major-related materials. All of them major in international finance or international trade. The reasons why the author choose Beihang University are based on: (1). BUAA is a renowned key university in China, and its learners and faculty pertain to advanced level, so it is available to ensure the quality of learners as well as curricula in international standard; (2). School of Economics and Management in BUAA pays more attention to improve learners' English proficiency, and in addition to the specialized English course, the school also offers several specialized courses in English, to some extent, to ensure the learners' English proficiency, especially the ability to read English literature; (3). As one of pioneers of the National College English reform, BUAA owns natural advantages in college English teaching, and learners' English proficiency is generally higher than that of learners in non-pilot universities. CUBoulder has a relative high rank among public universities in the US and similar to BUAA, CUBoulder is also famous for sciences. Both universities have gender distribution in common, that is, the number of male learners is higher than that of females.

What's more, the author used College English Test 4 (CET4) as a main indicator to reflect Chinese students' English proficiency. Those whose scores were under 425 (unqualified) were excluded from this study. In addition, the author took those undergraduate learners passing CET6 $(\geq 425)$ as proficient non-native learners to compare with native English learners. Finally, there were totally 92 Chinese students taking part in the investigation and 73 are qualified (CET4 $\geq 425$ ). All of Chinese learners had passed CET4 and their self-reported scores range from 428 to 649 with a mean of 531.28, while 34 of them also got the certification of CET6 with the average score of 546.7. And a course of English in Economics was arranged in the third year to help them read major-related materials.

When it comes to American learners, a total of 84 learners participated in the test and 76 questionnaires were valid. Among these 76 learners, their self-reported English scores in ACT varied from 22 to 35 with a mean of 28.53 . Considering their English scores in ACT, 34 proficient learners were picked out (English scores in ACT $\geq 30$ ).

\section{Instrument}

The Survey of Reading Strategies (SORS) is adopted to measure the perceived use of the type and frequency of strategies by post-secondary learners while reading academic materials in English typically encountered in secondary school and college. The SORS consists of 28 items, in the form of a five-point Likert scale ranging from 1 ("I never or almost never do this") to 5 ("I always or almost always do this"). A background questionnaire was administered along with the SORS statements, asking learners to provide information about their age, gender, and scores of CET 4 and 6 for Chinese learners and ACT scores for American learners in reading English. The SORS measures three broad categories of reading strategies, namely, meta-cognitive strategies (10 items), cognitive strategies (12 items), and support strategies (6 items) (See Appendix)

\section{Data Collection Procedure}

The SORS instrument was administered to the subjects in a similar way in China and the US. It was administered during a regular class period, with the help of the classroom instructors who were familiar with the overall objective of the research project. After a brief overview of the purpose of the study, a description of the instrument, and an explanation of the steps involved in completing it, the learners were instructed to read each of the 28 statements in the SORS inventory, and circle the number which best described their perceived use of the strategies. On the average, the US learners completed it in 12 minutes, while it took the Chinese learners nearly 16 minutes.

\section{RESULTS}

After collecting the data and discarding the invalid ones, 149 (73 in China and 76 in the US) valid questionnaires had been chosen for data analyses. All data were inputted in SPSS 13.0 (Statistical Package for the Social Science), where 
descriptive analyses, independent sample t-test were conducted. In regard to all statistical analyses, the significance value is defined as $\mathrm{P}=0.05$.

\section{A. Overall Use of Reading Strategies}

In Table 3.1 MRS, CRS and SRS are used to describe the integrated trend of meta-cognitive, cognitive and support reading strategies. Chinese learners report a more frequent use of all three categories than the US learners. Except CRS whose mean equals 3.58 for Chinese student, all the rest strategies are used at medium level. Therefore, it can be seen that the mean of ORS in the two groups all fall into medium level.

TABLE 3.1

DIFFERENCES IN THE USE OF ORS BETWEEN THE US AND CHINESE LEARNERS

\begin{tabular}{|l|l|l|l|l|l|l|l|}
\hline & & US & \multicolumn{2}{l|}{ CHN } & & \multirow{2}{*}{ Sig. } \\
\cline { 3 - 6 } items & Strategy & $\mathrm{M}$ & S.D. & M & S.D. & & t \\
\hline MRS & Meta-cognitive reading strategies & 3.24 & 0.406 & 3.34 & 0.464 & -1.330 & 0.186 \\
\hline CRS & Cognitive reading strategies & 3.45 & 0.356 & 3.58 & 0.416 & -2.112 & 0.036 \\
\hline SRS & Support reading strategies & 2.56 & 0.576 & 3.16 & 0.562 & -6.389 & 0.000 \\
\hline ORS & Overall reading strategies & 3.09 & 0.349 & 3.36 & 0.363 & -4.712 & 0.000 \\
\hline
\end{tabular}

With the exception of MRS ( $\mathrm{p}=0.186$ ), the $\mathrm{p}$ values of the rest two categories indicate statistically significant differences between the two groups, esp. SRS with $\mathrm{p}=0.000$. As a result, significant differences of ORS ( $\mathrm{p}=0.000)$ exist between the US and Chinese learners.

B. Differences in the Use of Meta-cognitive Reading Strategies

TABLE 3.2

DIFFERENCES IN THE USE OF MRS BETWEEN THE US AND CHINESE LEARNERS

\begin{tabular}{|l|l|l|l|l|l|l|l|}
\hline \multirow{2}{*}{ items } & \multirow{2}{*}{ Strategy } & \multicolumn{2}{|l|}{ US } & \multicolumn{2}{l|}{ CHN } & \multirow{2}{*}{ Sig. } \\
\cline { 3 - 6 } & & M & S.D. & M & S.D. & & \\
\hline M1 & Setting Purpose for reading & 3.37 & 1.069 & 3.44 & 1.014 & -0.409 & 0.683 \\
\hline M2 & Previewing text before reading & 2.75 & 1.287 & 3.45 & 1.119 & -3.548 & 0.001 \\
\hline M3 & Checking how text content fits purpose & 3.39 & 1.059 & 3.40 & 1.127 & -0.014 & 0.989 \\
\hline M4 & Noting text characteristics & 2.79 & 1.170 & 2.96 & 1.123 & -0.901 & 0.369 \\
\hline M5 & Determine what to read & 3.08 & 1.124 & 3.48 & 1.094 & -2.107 & 0.037 \\
\hline M6 & Using text features & 3.22 & 1.115 & 3.45 & 1.248 & -1.179 & 0.240 \\
\hline M7 & Using context clues & 3.18 & 1.104 & 3.30 & 1.037 & -0.667 & 0.506 \\
\hline M8 & Using typographical aids & 3.96 & 0.999 & 3.12 & 1.269 & 4.279 & 0.000 \\
\hline M9 & Predicting or guessing text meaning & 3.39 & 1.034 & 3.51 & 1.069 & -0.651 & 0.516 \\
\hline M10 & Confirming predictions & 3.08 & 1.080 & 3.25 & 1.115 & -0.932 & 0.353 \\
\hline
\end{tabular}

From Table 3.2, it could be found that apart from M8: Using typographical aids, Chinese learners demonstrate a more frequent use of the 9 remaining meta-cognitive reading strategies $(t<0)$; and, the means of all MET for Chinese and American learners are above 2.40 falling into medium level, which indicates a moderate use of MET while reading; there is only one MET--M8 lying in high level in the US learners' responses.

Independent samples t test shows that 3 of the 10 MET reveal statistically significant differences between two groups, including M2 ( $\mathrm{p}=0.001)$ : Previewing text before reading, M5 ( $\mathrm{p}=0.037)$ : Determine what to read, M8 $(\mathrm{p}=0.000):$ Using typographical aids. Among them, M2 ( $\mathrm{p}=0.001, \mathrm{t}=-3.548)$ and $\mathrm{M} 5(\mathrm{p}=0.037, \mathrm{t}=-2.107)$ are the two strategies more often used by Chinese learners than the US learners, but M8 $(\mathrm{p}=0.000, \mathrm{t}=4.279)$ represents an opposite tendency. In other words, Chinese learners would like to plan their awareness as a whole before reading and the US learners prefer noticing typographical characteristics while reading. In addition, both M2 ( $\mathrm{p}=0.001)$ and M8 $(\mathrm{p}=0.000)$ indicate more significant difference than M5 ( $\mathrm{p}<0.05)$. Finally, besides these differences, through t-test we can still observe the relatively balanced preference for M1 $(\mathrm{p}=0.683)$ and M3 $(\mathrm{p}=0.989)$.

\section{Differences in the Use of Cognitive Reading Strategies}

In Table 3.3, it can be seen that none of the 12 CRS is used in low level by Chinese and the US learners and 6 of 12 COG for the US learners and 8 of 12 COG for Chinese learners reached high level used strategies. Chinese learners report better use of 8 items than that of the US learners, while the US learners do well in the other 4 COG. The highest frequency of strategy use in each group concerns about attention to the reading process, comprising C4 (Trying to stay focused on reading) for the US learners and C6 (Paying close attention to reading) for Chinese learners. Chinese learners report a minimum level use of $\mathrm{C} 2$ (Reading aloud when text becomes hard) while C9 (Evaluating what is read) is the least used one reported by the US learners. It is worthy of being noticed that the US learners demonstrate a little stronger central tendency in both top and bottom strategies with standard deviation of 0.792 (C4 in the US) to 1.013 (C6 in China) and 1.044 (C9 in the US) to 1.310 (C2 in China). Generally speaking, compared with MRS, the US learners have a better central tendency in the use of CRS than Chinese learners. 
TABLE 3.3

DIFFERENCES IN THE USE OF COG BETWEEN THE US AND CHINESE LEARNERS

\begin{tabular}{|l|l|l|l|l|l|l|l|}
\hline \multirow{2}{*}{ items } & \multirow{2}{*}{ Strategy } & US & \multicolumn{2}{l|}{ CHN } & \multirow{2}{*}{ Sig. } \\
\cline { 3 - 6 } & & $\mathrm{M}$ & $\mathrm{S} . \mathrm{D}$. & $\mathrm{M}$ & $\mathrm{S} . \mathrm{D}$. & & \multirow{2}{*}{ t } \\
\hline C1 & Using prior knowledge & 3.34 & 0.464 & 3.81 & 0.995 & -2.165 & 0.032 \\
\hline C2 & Reading aloud when text becomes hard & 3.09 & 1.358 & 2.92 & 1.310 & 0.797 & 0.427 \\
\hline C3 & Reading slowly and carefully & 3.58 & 0.970 & 3.58 & 1.040 & 0.022 & 0.983 \\
\hline C4 & Trying to stay focused on reading & 3.99 & 0.792 & 3.85 & 0.967 & 0.948 & 0.345 \\
\hline C5 & Adjusting reading rate & 3.95 & 0.965 & 3.85 & 1.023 & 0.602 & 0.548 \\
\hline C6 & Paying close attention to reading & 3.89 & 0.988 & 4.03 & 1.013 & -0.809 & 0.420 \\
\hline C7 & Pausing and thinking about reading & 3.18 & 1.042 & 3.07 & 1.097 & 0.660 & 0.510 \\
\hline C8 & Visualizing information read & 3.55 & 1.012 & 3.75 & 0.969 & -1.236 & 0.218 \\
\hline C9 & Evaluating what is read & 2.63 & 1.044 & 3.03 & 1.067 & -2.289 & 0.023 \\
\hline C10 & Resolving conflicting information & 2.82 & 0.962 & 3.45 & 0.958 & -4.044 & 0.000 \\
\hline C11 & Re-reading for better understanding & 3.80 & 0.994 & 3.90 & 1.030 & -0.612 & 0.541 \\
\hline C12 & Guessing meaning for unknown words & 3.47 & 1.026 & 3.78 & 1.109 & -1.756 & 0.081 \\
\hline
\end{tabular}

T-test shows that three strategies indicate statistically significant differences, namely $\mathrm{C} 1$ : Using prior knowledge $(\mathrm{p}=0.032), \mathrm{C} 9$ : Evaluating what is read $(\mathrm{p}=0.023)$ as well as $\mathrm{C} 10$ : Resolving conflicting information $(\mathrm{p}=0.000)$, among which $\mathrm{C} 10$ shows the greatest significance. In particular, Chinese learners report more frequent use of the three strategies $(\mathrm{t}<0)$. Besides, learners in two groups show approaching preference to $\mathrm{C} 3$ ( $\mathrm{p}=0.983$ ), followed by $\mathrm{C5}$ $(\mathrm{p}=0.548)$, and $\mathrm{C7}(\mathrm{p}=0.510)$; in addition, apart from $\mathrm{C} 7$ which lies in medium level reported by both groups' learners, both $\mathrm{C} 3$ and $\mathrm{C} 8$ are used in high frequency. Although not achieving statistical significance, $\mathrm{C} 12(\mathrm{t}=-1.756, \mathrm{p}=0.081)$ can still be seen as a higher frequency by Chinese learners.

D. Differences in the Use of SUP Reading Strategies

TABLE 3.4

DIFFERENCES IN THE USE OF SUP BETWEEN THE US AND CHINESE LEARNERS

\begin{tabular}{|l|l|l|l|l|l|l|l|}
\hline \multirow{2}{*}{ items } & \multirow{2}{*}{ Strategy } & US & \multicolumn{2}{l|}{ CHN } & \multirow{2}{*}{ t } & \multirow{2}{*}{ Sig. } \\
\cline { 3 - 7 } & & M & S.D. & M & S.D. & & \\
\hline S1 & Taking notes while reading & 2.09 & 1.122 & 2.73 & 1.182 & -3.360 & 0.001 \\
\hline S2 & Underlining information in text & 3.21 & 1.320 & 3.66 & 1.216 & -2.148 & 0.033 \\
\hline S3 & Using reference materials & 2.57 & 1.124 & 3.49 & 1.192 & -4.889 & 0.000 \\
\hline S4 & Paraphrasing for better understanding & 2.55 & 1.112 & 2.84 & 1.143 & -1.532 & 0.128 \\
\hline S5 & Going back and forth in text & 2.54 & 1.076 & 3.42 & 0.971 & -5.265 & 0.000 \\
\hline S6 & Asking oneself questions & 2.40 & 0.955 & 2.81 & 1.089 & -2.389 & 0.018 \\
\hline
\end{tabular}

Table 3.4 shows that all the bottom 5 strategies for the US learners come from SUP and for Chinese learners, most of SUP $(60 \%)$ fall into the bottom 5 strategies. S1 (Taking notes while reading) in each group is ranked at the last place in all 28 strategies with 2.09 in the US and 2.73 in China. Unlike MET and COG, SUP indicate the lowest frequency of all, that is, 2 of 6 SUP are at low level and the remaining 4 fall into medium level for the US learners; for Chinese learners, though S2 reaches high level, all of the rest strategies fall into medium level.

In terms of independent samples t-test, two points are worth noting: 1) all the t values are negative, in other words, Chinese learners use all the 6 SUP more frequently than the US learners; 2) Except S4:Paraphrasing for better understanding, 5 of 6 SUP are statistically significant, including S1:Taking notes while reading ( $\mathrm{p}=0.001$ ), $\mathrm{S} 2:$ Underlining information in text $(\mathrm{p}=0.033), \mathrm{S} 3:$ Using reference materials $(\mathrm{p}=0.000), \mathrm{S} 5:$ Going back and forth in text $(\mathrm{p}=0.000)$ and S6:Asking oneself questions $(\mathrm{p}=0.018)$.

\section{E. Most Often Used Reading Strategies Reported}

TABLE 3.5

READING STRATEGIES USED MOST OFTEN BY THE US AND CHINESE LEARNERS

\begin{tabular}{|c|c|c|c|c|c|c|c|}
\hline \multicolumn{4}{|l|}{ US } & \multicolumn{4}{|l|}{$\mathrm{CHN}$} \\
\hline items & strategy & $\mathrm{M}$ & S.D. & items & strategy & $\mathrm{M}$ & S.D \\
\hline $\mathrm{C} 4$ & Trying to stay focused on reading & 3.99 & 0.79 & C6 & Paying close attention to reading & 4.03 & 1.01 \\
\hline M8 & Using typographical aids & 3.96 & 1.00 & $\mathrm{C} 11$ & Re-reading for better understanding & 3.90 & 1.03 \\
\hline $\mathrm{C} 5$ & Adjusting reading rate & 3.95 & 0.97 & $\mathrm{C} 4$ & Trying to stay focused on reading & 3.85 & 0.97 \\
\hline C6 & Paying close attention to reading & 3.89 & 0.99 & $\mathrm{C} 5$ & Adjusting reading rate & 3.85 & 1.02 \\
\hline $\mathrm{C} 11$ & $\begin{array}{l}\text { Re-reading for better } \\
\text { understanding }\end{array}$ & 3.80 & 0.99 & $\mathrm{C} 1$ & Using prior knowledge & 3.81 & 0.99 \\
\hline \multicolumn{2}{|l|}{ Total } & 3.92 & 0.08 & \multicolumn{2}{|l|}{ Total } & 3.89 & 0.09 \\
\hline
\end{tabular}

In the regard of five most often used reading strategies, an obvious similarity could be found among learners from two different countries. That is, they have 4 of 5 most often used strategies in common though the means of 4 items have a little difference. And neither of the dispersion degrees representing analogic similarity varies a lot. To average means of the five most often used strategies, the author obtains almost equal means of 3.92 to 3.89. Among the five strategies, both Chinese and the US learners prefer selecting CRS accounting for $100 \%$ and $80 \%$ respectively. 
As for the US learners, one MRS is ranked at the second place, while there are no MRS in Chinese group. It is interesting that Chinese learners rank C6 and C11 at the first and second place while the US learners place them at the fourth and fifth place. And C5 almost owns the same rank between the two groups.

\section{F. Least Often Used Reading Strategies Reported}

TABLE 3.6

READING STRATEGIES LEAST OFTEN USED BY THE US AND CHINESE LEARNERS

\begin{tabular}{|c|c|c|c|c|c|c|c|}
\hline \multicolumn{4}{|l|}{ US } & \multicolumn{4}{|l|}{$\mathrm{CHN}$} \\
\hline item & strategy & $\mathrm{M}$ & S.D. & name & strategy & $\mathrm{M}$ & S.D \\
\hline S3 & Trying to stay focused on reading & 2.57 & 1.12 & C9 & Paying close attention to reading & 3.03 & 1.07 \\
\hline S4 & $\begin{array}{l}\text { Paraphrasing for better } \\
\text { understanding }\end{array}$ & 2.55 & 1.11 & M4 & Noting text characteristics & 2.96 & 1.12 \\
\hline S5 & Going back and forth in text & 2.54 & 1.08 & $\mathrm{~S} 4$ & $\begin{array}{l}\text { Paraphrasing for better } \\
\text { understanding }\end{array}$ & 2.84 & 1.14 \\
\hline S6 & Asking oneself questions & 2.40 & 0.96 & S6 & Asking oneself questions & 2.81 & 1.09 \\
\hline S1 & Taking notes while reading & 2.09 & 1.12 & S1 & Taking notes while reading & 2.73 & 1.18 \\
\hline \multicolumn{2}{|l|}{ Total } & 2.43 & 0.20 & \multicolumn{2}{|l|}{ Total } & 2.87 & 0.12 \\
\hline
\end{tabular}

Table 3.6 presents the bottom 5 individual reading strategy preferences of learners in China and the US placed in descending order by their means. It could be seen that SRS are least often used strategies or least favored strategies (US learners 100\%, Chinese learners 60\%). Among those SRS above, the two groups share three strategies (S4IS5\S1) with nearly equal means. Means of the least used strategies in two groups are all above 2.40, that is, both of them fall into medium level.

In the US group, 2 of 5 strategies lie in low level (MeanS6=2.38, MeanS1=2.07), on the contrary, all the five strategies of Chinese group are at medium level. Chinese learners rank C9 and M4 at the first and second place but neither of them could be found in the US group. Though the means of least used strategies in two groups are at medium level, it is obvious that the mean of Chinese group is significantly higher than that of the US group.

\section{Discussion}

In order to answer Question 1, the author performs a series of descriptive analyses which are used to present type and frequency of reading strategy while reading major-related materials reported by Chinese and the US learners through the SORS, followed by independent t-test to examine whether significant differences exist between Chinese and the US learners. The results reveal three major findings worthy of note. These findings are summarized as follows:

\section{A. Overall Reported Strategy Use}

The data obtained concerning overall English reading strategy use show that both Chinese and the US learners demonstrate a moderate to high level of strategy use despite the differences found between the two groups that the Chinese learners report a slightly higher overall strategy use level than their American counterparts. The similarities in overall reported strategy use between the two groups are quite intriguing.

One possible explanation is that these learners are presumably skilled learners as indicated by the selection of learners (All of Chinese learners are chosen from a key Chinese university and those who haven't passed CET4 are excluded; the US learners all come from University of Colorado Boulder which ranks in the forefront of the public universities with relatively strict academic requirements). In order to meet the research needs greatly, all of the subjects are undergraduate seniors (in China) and juniors (in the US), therefore their abilities to use and understand reading strategy are better than freshmen and sophomores. In other words, all students under the investigation are considered to have medium to high level English proficiency, which may lead to difference in their English reading strategy use.

Secondly, the SORS is used here to examine learners at home and abroad using English reading strategy while reading major-related materials. That is, relative to other materials, learners would pay more attention to major-related materials, and they are exposed to these kinds of academic environment more often. So they are accomplished in using reading strategies for major-related materials.

Thirdly, compared with EFL learners, the US learners use English in a quite natural situation with low and moderate emphasis on reading strategy at college level, while Chinese learners who learn English as a foreign language have learned more and more English reading strategies through English tests and English teaching at college level. That is why Chinese learners have a slightly higher reported strategies use than the US learners. In addition, Chinese learners are all undergraduate seniors compared to undergraduate juniors in the US, so that also makes Chinese learners benefit a little bit more than their American counterparts.

\section{B. Overall Reported Strategy Preference}

Of the 28 reading strategies covering three main categories, the US and Chinese learners exhibit the same preference towards cognitive reading strategy, in other words, all of them report invoking a moderate to high strategy awareness level with a clear preference for using CRS, followed by MRS, and SRS. What's more, $100 \%$ of SRS fall into the bottom 5 individual reading strategies in the US group and 60\% of SRS are the same in Chinese group; however, $100 \%$ 
of CRS are found to be the top 5 individual reading strategies in Chinese group and $80 \%$ of CRS are found to be favored in the US group.

The reason why they demonstrate this equal preference is not surprising. All participants rely more on CRS while working directly with the processing of information in order to learn. It could be said that CRS play the most direct role in the procedure of reading aiming at solving problems; besides, CRS are also the most often tested strategies in English tests, as well as the most important strategies being taught in class.

Although strategic awareness and monitoring of the comprehension process are critically important aspects of skilled reading, only M8: Using typographical aids is ranked the second by the US learners, while Chinese learners even rank M4: Noting text characteristics at the second place among the bottom 5 strategies. The reason is partly because MET are in-direct strategy. As is mentioned above, it is mainly used to monitor readers' reading process. Therefore, it requires more self-awareness which is hard to grasp without systematic training.

Both Chinese and the US learners rank SUP at the least used level. The reason is probably that, traditionally, SUP are regarded as time-consuming strategies, which can't meet reading requirements and slows down the reading speed. Unless the materials are hard enough to read, learners won't select SUP consciously.

\section{Individual Strategy Use}

The major distinction between the US and Chinese learners' reported use of strategies are cognitive reading strategies and support reading strategies, with the means of Chinese group for CRS and SRS being considerably higher than those of their American counterparts.

As is shown before, MRS play the role of adjusting and monitoring learners' English reading, which requires a certain degree of self-control and self-awareness. Therefore, in general, both groups report medium use of MRS, and the differences in meta-cognitive reading strategy $(\mathrm{p}=0.186)$ are not statistically significant. However, significant differences still exist in M2, M5 and M8, and among them, M2 and M5 imply a better use of the two strategies by Chinese learners than that of the US learners $(t<0)$, but M8 represents an opposite tendency $(t>0)$. In other words, Chinese learners would like to plan their reading as a whole before task and the US learners prefer noticing typographical characteristics while reading. The reason for the above differences may be resulted from American learners' reasoning method, that is, the US learners are good at analogy; besides, the low reported use of M8 for Chinese learners may have something to do with differences in the way the US and Chinese textbooks are written, Textbooks produced in the US are more likely than Chinese textbooks to use features such as italics, bold face, and tables as a way of organizing and presenting information.

For CRS, problem solving is the main purpose for readers' use of CRS while working directly with text, so CRS selection is partly due to difficulty which readers may encounter. Chinese learners report significantly higher use of $\mathrm{C} 1$, C9, C10 and C12 than the US learners, because, compared with the US learners, Chinese learners have more chances to meet difficult words, sentences and expressions while reading in English; in addition, English test and teaching stress the use of CRS in China to some extent. In order to get a better understanding of reading materials, Chinese learners may utilize more prior knowledge $(\mathrm{C} 1)$ and evaluate the target materials $(\mathrm{C} 9)$ at any time, when encountering problems, they try to resolve conflicting information (C10) and guess meaning of unknown words $(\mathrm{C} 12)$.

Similar to CRS, SRS refer to basic support mechanism to aid readers while reading. The entire SRS are significantly different between the two groups with the exception of $\mathrm{S} 4(\mathrm{p}=0.100)$. For the sake of maintaining reading speed and obtaining information as much as possible, learners in both groups tend to report SUP at low frequency. However, learning English as foreign language exerts much more influence on Chinese learners to solve problems especially when they are novice readers. So, though ranking SUP at bottom level, learners in China still have a higher use of them than the US learners. S4 (Paraphrasing for better understanding) is the toughest and most complicated item ranked at low level by two groups.

\section{CONCLUSION}

In this study, the author attempts to describe the type and frequency of strategy use reported by both Chinese and the US learners, to examine whether significant differences exist in strategy use between Chinese and the US learners. Through conducting independent samples t-test, this present study reports Chinese learners have shown a moderate to high level strategy use in their major-related reading, which is clearly higher than the US learners in general. From the findings, the authors hope that Chinese learners may learn some lessons from American learners and employ some effective strategies to facilitate their academic reading.

APPENDIX. SURVEY OF READING STRATEGIES (SORS)

\section{Part one}

Name:

Scores in CET4:

English scores in ACT:

Part two
Gender: Major: Age:

Scores in CET6: 
The purpose of this survey is to collect information about the various techniques you use when you read major-related materials in English (e.g., reading textbooks for homework or examinations, reading journal articles, etc). Each statement is followed by five numbers 1, 2, 3, 4, and 5, meaning.

" 1 " means "I never or almost never do this."

"2" means "I do this only occasionally."

" 3 " means "I sometimes do this" (about $50 \%$ of the time).

"4" means "I usually do this."

"5" means "I always or almost always do this."

After reading each statement, circle the number $(1,2,3,4$, or 5) which applies to you. Note that there are no right or wrong responses to any of the items on this survey.

\begin{tabular}{|c|c|c|}
\hline & & STATEMENT \\
\hline MET & 1 & I have a purpose in mind when I read. \\
\hline SUP & 2 & I take notes while reading to help me understand what I read. \\
\hline COG & 3 & I think about what I know to help me understand what I read. \\
\hline MET & 4 & I take an overall view of the text to see what it is about before reading it. \\
\hline COG & 5 & When text becomes difficult, I read aloud to help me understand what I read. \\
\hline MET & 6 & I think about whether the content of the text fits my reading purpose. \\
\hline COG & 7 & I read slowly and carefully to make sure I understand what I am reading. \\
\hline MET & 8 & I review the text first by noting its characteristics like length and organization. \\
\hline COG & 9 & I try to get back on track when I lose concentration. \\
\hline SUP & 10 & I underline or circle information in the text to help me remember it. \\
\hline COG & 11 & I adjust my reading speed according to what $\mathrm{I}$ am reading. \\
\hline MET & 12 & When reading, I decide what to read closely and what to ignore. \\
\hline SUP & 13 & I use reference materials(e.g., a dictionary)to help me understand what I read. \\
\hline COG & 14 & When text becomes difficult, I pay closer attention to what I am reading. \\
\hline MET & 15 & I use tables, figures, and pictures in text to increase my understanding. \\
\hline COG & 16 & I stop from time to time and think about what I am reading. \\
\hline MET & 17 & I use context clues to help me better understand what I am reading. \\
\hline SUP & 18 & I paraphrase (restate ideas in my own words) to better understand what I read. \\
\hline COG & 19 & I try to picture or visualize information to help remember what I read. \\
\hline MET & 20 & I use typographical features like boldface and italics to identify key information. \\
\hline COG & 21 & I critically analyze and evaluate the information presented in the text. \\
\hline SUP & 22 & I go back and forth in the text to find relationships among ideas in it. \\
\hline COG & 23 & I check my understanding when I come across new information. \\
\hline MET & 24 & I try to guess what the content of the text is about when I read. \\
\hline COG & 25 & When text becomes difficult, I re-read it to increase my understanding. \\
\hline SUP & 26 & I ask myself questions I like to have answered in the text. \\
\hline MET & 27 & I check to see if my guesses about the text are fight or wrong. \\
\hline COG & 28 & When I read, I guess the meaning of unknown words or phrases. \\
\hline
\end{tabular}

\section{REFERENCES}

[1] Alsheihk, N. O. \& Mokhtari, K. (2011). An examination of the meta-cognitive reading strategies used by native speakers of Arabic when reading in English and Arabic. English Language Teaching. 4/2: 151-160

[2] Anderson, N. J. (1999). Exploring Second Language Reading: Issues and Strategies. Boston: Heinle \& Heinle.

[3] Barnett, M. A. (1988). Reading through context: How real and perceived strategy affects L2 comprehension. The Modern Language Journal. 72(2): 150-162.

[4] Block, E. (1986). The comprehension strategies of second language readers. TESOL Quarterly, 20: 463-494.

[5] Block, E. (1992). See how they read: Comprehension monitoring of L1 and L2 readers. TESOL Quarterly, 26:319-343.

[6] Carrell, P. L. (1989). Meta-cognitive awareness and second language reading. The Modern Language Journal, 83/3: 319-338

[7] Carrell, P., B. Pharis \&J. Liberto. (1989). Meta-cognitive strategy training for ESL reading. TESOL Quarterly 23: 647-678.

[8] Grabe, W. (1991). Current developments in second language reading research. TESOL Quarterly 25/3: 375-405

[9] Hedge, T. (2002). Teaching and learning in the Language Classroom. Shanghai: Shanghai Foreign Language Education Press.

[10] Liu Shan \& Zuo Niannian. (2006). The influence of cognitive style and reading strategies on English reading: an empirical study. Teaching English in China. 29/3: 56-63

[11] Mokhtari, K. \&R. Sheorey. (2002). Measuring ESL learners' perceptions of their reading strategies. Journal of Development Education 25/3:2-10.

[12] Olshavsky, J. E. (1976-1977). Reading as problem-solving: An integration of strategies. Reading Research Quarterly, 12: 654-674.

[13] Silberstein, S. (2002). Techniques and Resource in Teaching Reading. Shanghai: Shanghai Foreign Language Education Press. 
Jianfeng Zheng, Professor of English, Supervisor of Foreign Linguistics and Applied Linguistics. She has been teaching English as a foreign language in China at Shanxi Normal University for about 30 years. Her major interests are in language teaching and language learning strategies. She is also interested in Pragmatics and Discourse Analysis. In the past decade, she has published 20 articles in the above mentioned fields.

Ning Kang, a graduate student majoring in Curriculum and Teaching at Shanxi Normal University during 2011—2013. 